\title{
DIETARY ADAPTATION OF SOUTHERN IN-MI- GRANTS IN NORTHERN CITIES OF NIGERIA
}

\author{
John Odihi \\ Department of Geography, University of Maiduguri, Maiduguri, Nigeria
}

\begin{abstract}
In Nigeria there exist a zonation of dietary patterns which mirror the ecological zones (biohydroclimatic conditions) and cultural practices in the CQWB-, try. However, dietary patterns of northern Nigeria cities are an exception to these general patterns. Empirical evidence suggests instead a remarkable dietary heterogeneity until now due to the access to native diets. Contemporary and growing problems of the Nigeria economy and their attendant social and transportation problems have posed problems for continued patronage of native diets by many in-migrants in northern cities. Consequently, more in-migrants are changing to the grain-based diets of the north. This dietary transition and the resulting dietary integration of urban population in the north have implications for crop production in Nigeria.
\end{abstract}

\section{Introduction}

Northern Nigeria cities are a melting pot of the country's populations as few, if any cities in the north, are without ethnic groups from alt parts of Nigeria. The presence of diverse ethnic population in northern cities is a result of economic and demographic factors, among others. The history of the important concentrations of southern inmigrants in northern cities if fairly recent but goes back to the colonial era when the colonial administration ensured peace by quelling long existing intra-tribal hostilities. The existence of peace, thanks to Pax Britannica, encourage integration of both the peoples and the areas of Nigeria making the nation to realise to a greater extent the economic advantages of its ecological and cultural diversity. Socio-economic integration of the diverse ecological and cultural zones of the country was also greatly aided by the building of roads and railways from coastal port cities to those of the interior (Onyemelukwe and Filani 1983, for the socio-economic importance of such roads in the West African region).

Of particular relevance to the concentration of southern in-migrants in northern cities were the establishment of Western institutions in areas of education, government, health and commerce among others, and the relative dearth of northern expertise and sometimes interest in working in such institutions which created opportunities for southern people. The southern populations had by the early period of colonial administration in the country had a considerable amount of contact with the West and acquired skills relevant to the interest of the colonial administration in the north. 


\section{Dietary Adaptation of Southern In-migrants in Northern Cities of Nigeria 34}

These southern people were therefore mainly the teachers in school, clerks In offices, workers in the railway stations and health care centres. They were also prominent in colonial government in northern Nigeria. Southern in-migrant populations were prominent enough to form distinct spatial identities in northern cities that their living quarters or wards in such cities were given the name "Sabon Gari" (Mabogunje 1968). To a lesser or greater extent, people of middle belt origin began to drift to northern cities in search of jobs and better life as such opportunities for them existed almost exclusively in northern cities where they belonged to politically.

It is this existence of the "micro Nigeria" in northern cities, the attachment to culture and the relative ease of obtaining one's native diet in northern cities that made such cities a culinary anomaly in the dietary patterns of the country. Instead of the grainbased dietary patterns of the Sudano-Sahelian belt, northern cities manifest a culinary diversity - a kaleidoscope of almost the entire Nigeria diets.

This paper presents the result of the investigation of the diets of southern and middle belt in-migrants in northern cities over time. It points out patterns of diets of the different groups at particular times and offers reasons for adherence to and/or transition from particular dietary patterns. The cities in which the investigation was carried out are Kano, (Kano State), Hadejia (Jigawa State), Potiskum, Gashua and Nguru (Yobe State) and Maiduguri (Borno State). At the start of this investigation in early 1991, these cities were in only two states -Kano and Borno. The choice of the cities was not based on particular factors other than the convenience of the investigator/author.

In view of the multiple uses of certain words in the social science literature and hence their imprecision or ambiguity, the operational definitions of some of the key words used in this paper are offered here. For this paper the term "migrant" refers to internal migrants within Nigeria (i.e. Nigerians from other areas or ethnic groups other than those who are indigenes of the northern dry belt or cities of the study). Southwestern in-migrants in the paper refer to indigenes of the southwest states, including Lagos, Edo, and Delta States. Similarly, southeastern in-migrants refer to southeastern states of Abia, Enugu, Anambra, Imo, Akwa Ibom, Cross River and Rivers. In-migrants of the middle belt refer to all indigenes of the former political north south of the belt defined by latitude $10^{\circ} \mathrm{N}$. Native diets are the staple food of an ethnic group or defined area which are based on their agricultural production. Dietary transition is a change from a native diet to a northern diet. Dietary adaptation refers to the adjustment to conditions of scarcity of native diets which makes in-migrants to adopt the grain-based diets of the north. Food items such as rice, beans, garri, ogi (akamu or pap) which are universal urban foods in Nigeria are not considered in the study. 


\section{Methods and Data}

A total of 1413 ill-migrants belonging to different socio-economic groups vv ere surveyed in the six study cities in urban residential quarter, including reservation areas (GRAs) and barracks, markets, mechanic villages and other areas. The specific numbers of people surveyed in particular cities are presented in below.

A total of 679 people were surveyed in the old Borno State (now Borno and Yobe States) as opposed to the 734 in the Kano State (now Kano and Jigawa). The survey south to understand the dietary habit or patterns of the respondents' household over time (i.e. past present and future) and the basis for the habit or pattern. Thus, the survey can be described as retrospective, contemporary and futuristic. Random sampling methods were used in the survey. This was facilitated by a prior inspection of the various areas (including markets and mechanic villages) of the different cities to determine the proportion of the in-migrants from different geographical regions of Nigeria. In each study area, a census was carried out in concentrations of in-migrants populations. The proportionate representation of each in-migrant population category was then used as a guide to determine their respective representation in the study sample.

The survey centered mainly on the dietary experience of the in-migrants both in the past (pre-1986) and the present (1987-93). It also sought to understand their perceived dietary habits in the future, assuming the continuation of present economic condition and their stay in the north. Respondents were asked to identify their native diet, their household diet in particular time period and to offer reasons for their ranking patronage

of, and preference for, native or northern diets. Surveys involving residents of cities also south information on their migration history (i.e. age of household in the north), household size, and estimates of household income. The methods of survey employed with respondents were the questionnaire method and interview schedules. The questionnaire administration involved those who were literate and willing to respond through that means while the interviews were held with people who were not literate or literate but opted for the interview method.

Long distance food trade drivers were interviewed in the study cities concerning their commodities, origin/history of playing the route, and frequency of trips over time. They were asked about changes in some of the parameters over time and about factors responsible for such changes. Similarly, wholesale and retail trade of food items imported from the south were surveyed in the markets concerning their wares, ethnic background or their customers and volume of trade overtime.

Reported household incomes were grouped into three categories of high, middle and low income brackets. The high income bracket includes all 
households whose per capita annual income was above N5000.00 in 1991. Middle and low income brackets were those household whose annual per capita income was between N1000 and N5000, and below N1000.00 respectively in 1991. Graphs and percentage are used to depict the dietary changes amongst different geographical groups of in-migrants over time.

\section{Findings}

The investigation of dietary patterns of in-migrants in northern cities reveals that for all geographical groups of in-migrants there are three discernible dietary phases. The first which is the longest of the phases is adherence to native diet and by implication an unwillingness to adopt northern diets. The second phase which for many respondents is a post-structural adjustment programme (SAP) experience began in 1987. The phase is characterised by a mixed dietary habit in which, to a lesser or greater extent, households subsist on both their native diets and the northern grain-based diets. For the purposes of this paper this phase is referred to as the dietary combination phase. The third or native diet weaning phase is characterised by more or less a lack of dependence on native diets. While households would be happy to have native food and may miss it, they are at the same time not so bothered by subsisting on the grain-based diets of the north. Table 1 shows zonal diversity of the native diets including beverages while Table 2 depicts the percentage of in-migrant in the different dietary phases overtime.

The critical period in the dietary transition experience of in-migrants was 1987. Before 1987, native diets accounted for almost 60 percent of the households' diets of inmigrants (about 63 percent for southerners and about 56 percent for in-migrant of middle belt origin). A total number of 1298 households (i.e. 91.86 percent made up of 1099 households of southern origin and 199 households of middle belt origin) said they maintained a near exclusive native diet pattern. The nature of the transition can be understood along geographical (ecological) zone or income lines. Universally, the change is towards northern grain-based diets and away from mostly native and sometimes imported diets. In households where exotic diets (i.e. food stuffs imported from abroad or locally processed food packaged sold on shelves in kiosks and superstores e.g. corn-meal, oatmeal, quaker oats, cornflakes, macaroni, noodles and baked beans) formed part of the household diets, such exotic foods were the first type of food to be discontinued or curtailed, These exotic foods were important in the dietary experience of 133 household up to 1987 but by the end of 1993 only 17"households considered them to be so. Eleven out of these 17 households would discontinue them from the list of their household diets if the price of these food items would continue to escalate. All households reporting exotic food items as part of their household diets belonged to the upper income 


\section{Dietary Adaptation of Southern In-migrants in Northern Cities of Nigeria 37}

Table 1 Selected Native Foods and Soups of ln-migrants Geographical Regions

\begin{tabular}{|c|c|c|}
\hline Region & Foods & Soups \\
\hline Middle Bell & $\begin{array}{l}\text { onihi, onihe, ibancha, } \\
\text { iya, uka, clicu. ach.i, } \\
\text { kiimc. rtiwan nalia }\end{array}$ & $\begin{array}{l}\text { okoho, obobo, (abahi, ocha, cho) } \\
\text { igbidu, uzi, cpipara, kikpi, Isokora. kidn. niwan }\end{array}$ \\
\hline $\begin{array}{l}\text { Southeast } \\
\text { abacha, npwu, akpi }\end{array}$ & $\begin{array}{l}\text { akpti, ikpan nkwukwo, } \\
\text { udort efete oho atama, } \\
\text { (cxva), inenji (ipoji), } \\
\text { USHII, bin, ayan ekpan, } \\
\text { olo, onunu. ibegbili }\end{array}$ & $\begin{array}{l}\text { afan, erere, ikon, edi kai ikon, } \\
\text { ofe afan, ofe nsala, ofe ede, } \\
\text { uha okazi, arara, achi }\end{array}$ \\
\hline $\begin{array}{l}\text { Southwest } \\
\text { lafun, a mala, boli.cbc, }\end{array}$ & $\begin{array}{l}\text { iyan: (isu, koko, ogede), } \\
\text { egusi, alakpa.obe eja tutu, } \\
\text { ikokorc, cko (agidi), } \\
\text { baga, owrevwi, ebe } \\
\text { oliili, ekuni. elemi nieje, } \\
\text { ojojo, dundun. ipekere, } \\
\text { eberipo eleti, lan'gbe, usi. Ema }\end{array}$ & $\begin{array}{l}\text { obe ijp, gbegiri, ewedu, (oyoj, } \\
\text { ogweri gbure, imoyo, obe panla, } \\
\text { obe sokoyokolo, gbagbafafo, ewaagbado (adalu), dodo, }\end{array}$ \\
\hline
\end{tabular}

\section{Source Field Work}

Table 1 Trend of Northern Diet Adoption by In-migrants in Selected Cities.

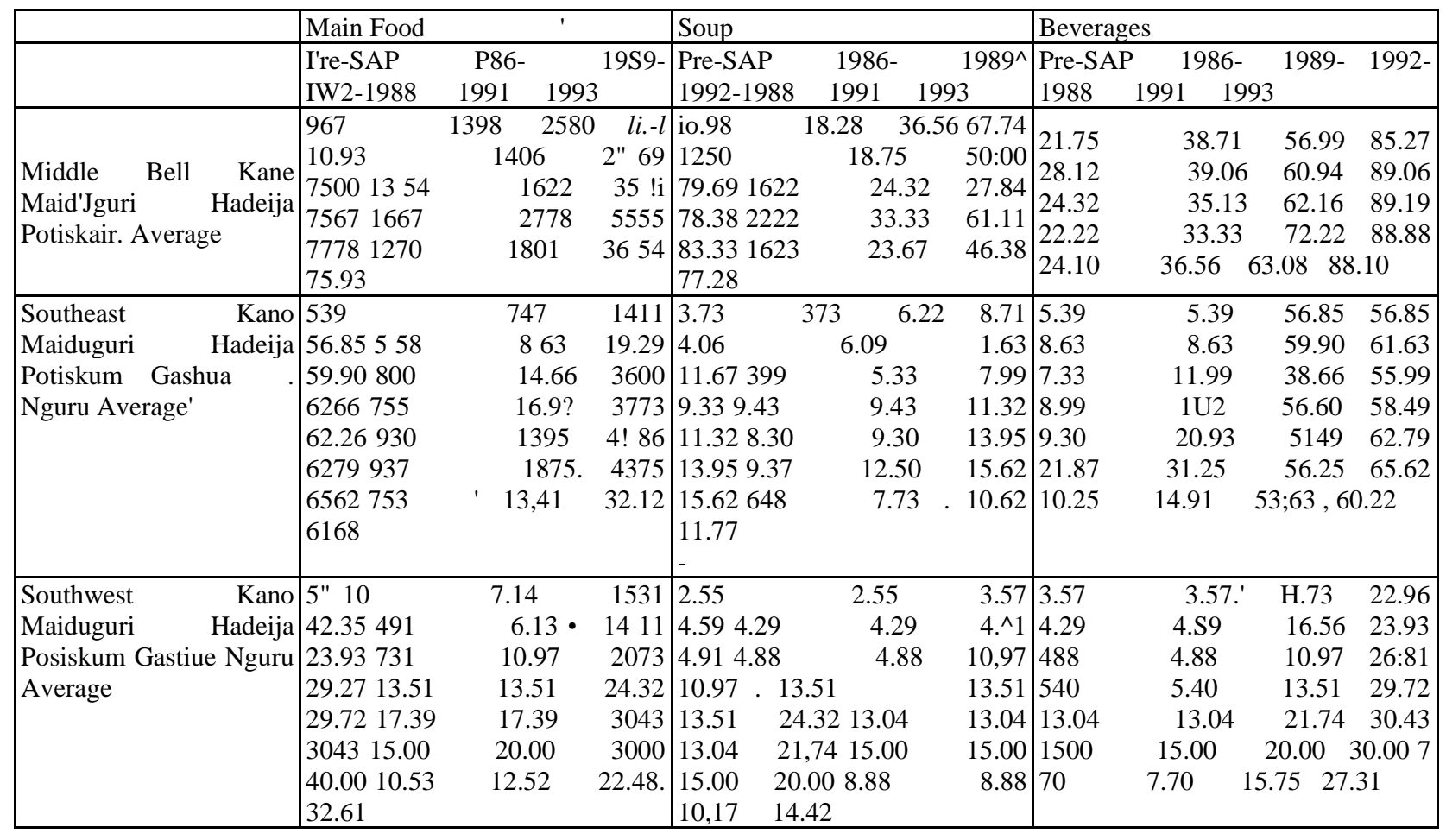


38 Annals of the Social Science Council of Nigeria, No. 8. January-December, 1996 
bracket.

Both the-degree (how much of northern diet is adopted by a household) and the rate of adoption (i.e. the proportion of households adopting northern diets in a defined unit of time) are not uniform. Different periods as well as in-migrant from different geographical areas manifest different change patterns. The first three years of SAP (198688) were marked by very little change or indifference as the majority of the in-migrant continued to subsist on their native or pre-SAP diets (see Table 2 and Figure la, b, c). There was almost a general two fold increase during the following three years (19891991). By 1993, about 75 percent of in-migrant of middle belt origin had wholly or substantially adopted the northern diet.

There are some interesting findings linking availability and prices of native food items to the size of study cities as well as their distance (measured in physical terms or in monetary costs) from the source regions of the native food items. For example, of all the source regions of the in-migrant native food items were most costly in Gashua and $\mathrm{N}$ guru where they cost between 20 to 30 percent higher than in Kano. Thus, there appears to be a relationship between availability and price of the food items and city size on the hand, and distance from source and unit price of food items on the other. While the relationship between city size and availability is linear and positive, the relationship between prices appears to be inverse. The relationship between city size and price which is a function of availability (supply) is generally inverse.

Maiduguri price appears to distort the general price pattern for both yam and plantain as Maiduguri prices for these items are generally higher than in other study cities. However, the survey revealed possible reasons for the distortion: Maiduguri is not a terminus for these principal items of food trade. Rather, Maiduguri is an important depot or collection centre of these items in the transformer food trade between Nigeria and its neighbours: Cameroon, Chad and Niger. It is estimated that between 30 to 40 percent of yam and plantain reaching Maiduguri would enter the transformer distribution network.

By 1993 differences in the degree of adoption could be seen both along geographical and income level lines: different in-migrant and income groups manifested different levels of adoption. For example over 90 percent of middle belt in-migrant belonging to the lower income bracket had adopted the northern diet. In place of yam and yam derived products for the main (heavy) menu, brands of tuwo such as corn, millet, sorghum or guinea corn are used. Fifty-seven out of the 231 household of the middle belt origin use northern soups or soup ingredients more often than their native ones. For both southeastern and southwestern in-migrant, the dietary change involves the heavy aspect of the diet. By 1985, before SAP was introduced, only 18 low income household (5.27 percent) of the southwestern ori gin claimed they were subsisting on the many brands of tuwo (e.g. tuwo masara, tuwo dawa, tuwo shinkafa etc). 
Thirty-seven household of southeastern origin (i.e. 5.68 percent) did the same.

By 1993 however, the situation had substantially changed for the southern low income household as a total of 364 households (219 households or 60.16 percent southeastern, and 145 households or 39.84 percent southwestern) were by then subsisting mainly on various brands of tuwo. The remaining low income and middle class households observed that they used mixed dietary time table (i.e. native and northern) guided by availability and affordability. Southern in-migrants are less eager to adopt northern soups. Only a total of 173 households (14.64 percent) were using northern brand of soup by 1993. Two factors were responsible: economics and taste. About 60 percent of the households not using northern soups based their non adoptation on the fact that their members did not like the northern soups and another 10 percent did not use them because preparation problem. The remaining non-user households did not make northern soups for a combination of all or some of these reasons.

Respondents' reasons for the observed pattern of their household diets can be classified into three. All respondents mentioned economic hardship. Only 31 out of a total of 1413 failed to identify SAP as the cause of their dietary modification or change. Nineteen households (in addition to their observation that unfavourable economic conditions were responsible for their dietary experience) mentioned that they were adopting northern diets because they liked it. The open-ended nature of the question permitted this seeming contradiction, but it is interesting and instructive to note that their adoption of northern diets postdated the introduction of the structural adjustment programme.

\section{Changes in Beverage Use}

Certain patterns are discernible in beverage consumption. Again, the pattern is both temporal and ethnic. The middle belt in-migrants generally claimed they were used to kunu in their native diet and that only the form of preparation and the taste differ from the northern type of kunu. The survey shows that most households of middle belt origin claimed they were using their own brand of kunu in their diet before SAP. Approximately 18 percent (42 households now make and use the northern brand in their households. These do so because of the simpler nature of the preparation of the northern brand and more ready availability of its ingredients. Some household making and using northern brand of kunu in their own house would not buy it outside because they could not be certain of the hygienic status of the environment of preparation or hawking. The fear about northern brand relates to its simple mode of preparation especially the lack of cooking or use of boiling 
water. Some respondents who described the northern brand as raw (uncooked) said that its consumption could pose health problem as water sources are not of high quality and commercial Iv -oriented production would use cheap water of low quality. However, respondents of middle belt origin are increasingly taking kunu in their places of work. Before SAP (i.e. ptr-1986), only about 15 percent of the respondents said they took kunu in their places of work while the corresponding figure 1993 is 87 percent.

One thousand and seventeen southern households (or 90.50 percent of them) were not previously accustomed to kunu. Most of the rest who were taking kunu were either born or brought-up in the north, and/or took kunu only outside their homes prior to SAP. Again, after the increase in the price of soft drinks such as Coke, Fanta, Pepsi, Krest, Seven up and GingerAle, southern in-migrants started adopting kunu. Only 21 households (or 3.23 percent) of southern origin observed that their members had taken kunu before 1986, out of which only eight households did use the product in their own houses. By 1989, 37 households were using it in their own house.

At the work place, kunu was fast replacing soft drinks such as Cock, Seven up and Pepsi as the favourite drink of the southeastern in-migrant. In motor spare-part retail areas and mechanic villages, southeastern in-migrants were switching to kunu because of its attractive prices. Kunu packs of 50k, N1 and N2 were available and the quantity of 50k kunu which was about 30cl in 1993 compared favourably with the 29cl of soft drink at N7 per bottle. Many apprentice respondents who had no salaries or allowances found kunu very attractive. Additionally, respondents argued that kunu served as food as it is filling and nutritious.

The change from soft drink to kunu was rather sudden and substantial. Before 1992, over 90 percent of southeastern in-migrants kunu users were taking bottled soft drinks such as Coke. As at 1993 a pattern was emerging. In many of the survey cities, southeastern in-migrants were also involved in the making and hawking of both middle belt and northern brands of kunu in public places such as markets, mechanic villages and petrol stations. The southwestern in-migrant appeared not to welcome kunu with the enthusiasm of the southeastern. Our survey shows that only nine households of southwestern origin were making kunu in their houses in 1993. Also less than 35 percent of them were taking kunu in their places of work. They preferred bottled soft drinks and kankara (ice water) to mitigate the effects of oppressive daytime temperatures or to quench their thirst.

In-migrants attitudes to other types of northern beverages appear more uniform. For example, there is no significant difference in the attitude of all groups of in-migrants towards yakwa drink as over 80 percent of all groups observed that they liked it. The yakwa drink ingredient which is dry buds and leaves of yakawa 
plant (Hibiscus Sabdariffa) are heavily patronized by all groups who buy them for their household use and for exporting to relatives or for trade elsewhere. The drink is fondly called Nigerian Ribena, Nigerian Currant or soporodo (soborodo) by respondents. Kunun gyada, a nutritious food drink made from groundnut with or without rice and fura da nono are respectively liked by about 80 percent 55 percent of middle belt in-migrants. Onlyabout 20 percent and 17 percent of southeastern in-migrants and southwestern inmigrants, respectively, like kunun gyada. Both groups of southern in-migrants are reluctant about using fura da nono. Their objection is based on their assessment of the environment for making and marketing the product as un-hygienic. These groups of respondents claimed that the environment is usually fly-infested and doubt the safety of taking the product.

\section{Out-of-House Eateries}

Our survey of hospitality places such as hotels and restaurants, and households reveals that hotels, restaurants and public events such as marriages, naming ceremonies (christening) and festivals are important sources of native diet for in-migrants. Restaurants operated by southwestern in-migrant would have amala, ewedu and efo, those by southeastern in-migrants would have akpu ("santana"), edi kaikon, ugusi and isewu, while those by the middle belters would have akoho and ohupi. Native food restaurants also usually have pepper soups that whet the native taste appetite of their customers.

Some respondents have the habit of eating native diets in restaurants during scarcity. They would on such occasions buy food for themselves alone. According to some respondents, the cost-free nature of public entertainment during festivals, marriage and naming ceremonies make such occasions important in the dietary link between poor immigrants and their native areas. This is more so as respondents (i.e. householders and restaurant operators) observed that the inflation problem and its resultant decline in native restaurant patronage would invariably affect native restaurant business. Respondent (i.e. both customers and operators of native diet restaurant) observed that 1993 prices of native dishes where on average about 300 percent above their 1986 levels. Many restaurants are operating below their pre-SAP levels while others have closed for lack of good business.

\section{Discussion}

Northern Nigerian cities are important meeting points where the people and cultures of Nigeria have interacted for many years since the advent of colonialism. It is not therefore surprising that there exists a tremendous ethnic and cultural diversity in such cities, a diversity which is manifested in the culinary experience of the cities. Culinary diversity in northern Nigeria cities results from two important 
factors: The taste for native diets, and the ready availability of native of food stuffs such urban markets far away from home. Since the mid-1980s, both of these factors have been seriously assailed by unfavourable economic factors.

At the root of the dietary diversity of Nigeria are the physical factors of the country's latitudinal spread through many ecological or climatic zones. The ethnic and cultural diversity of the country is another important factor. Together, the two factors of the physical and cultural environments confer on many eco-cultural areas a comparative advantage in the production of certain food crops (Agboola 1979; Nwafor 1982) upon which local diets of rural populations (Hinderer 1872; Turker 1853; Curtis 1965; Agboola 1979) and a lesser or greater extent that cultural and physical (natural environment). In other words, the power of geography in shaping human existence (Dear and Welch 1989).

The introduction of SAP into the Nigerian economy in 1986 has affected dietary pattern of long distance in-migrants through its effects on household income, inflation and general socio-economic security. Such effects of SAP are not peculiar to the study cities or Nigeria. The general as well as the specific effects of SAP in the Third world has received much attention in the development literature since the 1980s as the literature on the subject shows. The general SAP literature has been critical of the programme in the area of human well being, especially in relation to food (Stein and Naiziger 1991; and Steward 1990). Okpala (1992) showed that SAP adversely affected the Nigerian family and wondered why the programme was introduced at a time when the socio-economic signals least suggested it. The specific findings of this survey concerning the effects of SAP on the economy and as such effects relate to the diets of in-migrants in the northeastern states from the focus of discussion below.

SAP's effects on the transport sector of the Nigerian economy are many and deleterious, amounting to a near crippling of the sector and the socio-economic activities dependent on it. The inevitable hyper-inflation attending SAP in Nigeria due to the massive devaluation of the naira - a cardinal objective of SAP - has made it extremely difficult for transporters to buy new vehicles or maintain old ones to ply their routes. SAP has also affected the opening up of rural areas of the country, a recent trust of government development thinking. New rural roads cannot be constructed in many areas needing them for purposes of integration with the larger society or general development, nor is it easy to maintain old roads. The result is that many rural areas with much agricultural produce cannot be reached for many months in a year or cannot be reached at all (Odihi 1994a). Thus, Sap has increased the friction of distance between food producing or surplus food areas and areas of food demand or need, resulting in less food reaching urban areas, as well as creation of scarcity and price inflation. The 


\section{Annals of the Social Science Council of Nigeria, No. 8, January-December, 1996}

abandonment of some rural areas owing to bad roads reduces the possibility of their products reaching urban markets. Urban people dependent on native food from such areas have to switch to other types of food which are more readily available. These effects have made the operation of the SAP one of the factors responsible for what Amuwo (1992) called the Malthusian specter news of famine and other socio-economic problems so prevalent in parts of the African continent. The operation of the structural adjustment programme in Nigeria is also related to the factors that bear testimony to Munslow's (1991) observation concerning Africa that: "good news is an all too rare commodity to emanate from the Africa continent these days" (emphasis mine).

The structural adjustment programme is affecting the dietary integration of Nigeria urban population in the study area which many years of permanent migration and interaction between ethnic groups from different ecological zones did not do. As a result of this dietary integration, the dietary map of Niger will, for the first time, approximate climatic and related conditions in the country. The emerging homogenous dietary pattern in northern cities being effected by adverse socio-economic condition would now make it possible to delineate dietary zone in that part of Nigeria. I had noted that:

The existence of urban areas, their numbers and growing size of their populations and their distortion of the local dietary picture precluded "clean" dietary zone delineation, at least, in the north in the past. This is due to the fact that urban centres were of dietary anomaly against the general backdrop of the grain-based diet of the north in the past. (Odihi 1994b). The emerging dietary homogeneity in the country imposed by adverse socio-economic condition has implications for both food trade and food production in the country. Again, I had noted that though, theoretically, food production is expected to shrink in response to less favourable market conditions, this is however not an inevitable consequence and should not be the case in view of they many reasons in support of increased food production in both Nigeria and Africa at large (Odihi 1994b). There is a problem of persistent urban hunger in Nigeria which is growing $\mathrm{m}$ terms of the number of people falling victim to it, the seriousness of hunger problem elsewhere in Africa which environmental refugees fleeing from scarcity conditions in their country are evidence of, widespread malnutrition problem, and the international food trade begging for attention in the continent (Olatunbosun 1975; Odihi 1994c; IFPRI 1994; Odihi 1993; UNDP 1992).

The dietary transition of southern in-migrants in urban cities in the north is a proven case for boosting food production in the area in response to increased demand. The expanding market opportunities for northern grains should result in spatial expansion of agricultural production, temporal extension of food production activities or both. 
Agricultural production can be expanded through the incorporation of land in production. Foisting programme or structures such as the National Agricultural Land Development Authority (NA1-DA) can prove useful if adapted to the needs of the farmers. Fortunately, land resources are not a binding constraint on production in many parts of the study area to their relative abundance although such constraints exist in states like Kano (see Udo 1970, Cline-Cole et al 1990).

Temporal extension of agricultural production can be facilitated by expansion of irrigation programmes as water is the limiting condition to agricultural calendar in this dry belt. The provision of irrigation water will therefore extend the agricultural crops even in the dry season (Olofin 1991; 1993; 1994). What is needed to boost food production in some areas of the north, especially those in the leeward side of thriving irrigation schemes, is a willingness of irrigation scheme authorities to share water with downstream population and production programme as I have advocated (Odihi 1995). Such consideration of downstream interests would reduce some of the "pains" of putting the water look on the dry face of the north. The expensive nature of irrigation projects and prevalence of poverty conditions among farmers require that assistance be given to the farmers to respond appropriately to the need of more food production. The structures for this type of assistance are on ground in the form of the state Agricultural Development Projects (ADPs). These projects need to be fine tuned for better efficiency and effectiveness to make them relevant or responsive to the needs of farmers.

The concomitance of dietary transition in northern cities and widespread urban malnutrition problem in Niger which several recent UNICEF reports have highlighted is disturbing. One wonders how much of the malnutrition problem is a result of the dietary transition especially since types of northern diets with known valuable nutritional value are rejected by the in-migrants. Clearly, there is need for more research in this area. However, it is important to address the problem of rejection of quality food from the point of view of the rejecting in-migrants and the trading natives. The in-migrants' concern about sanitary status of the environment in which the project is marketed (e.g. attraction of flies to fura da nono) can be addressed effectively and easily. For example, the distribution chain can be shortened through direct buying from the dairy farmers; and sellers can be educated even by buyers to improve the sanitary condition of the environment and the regular cleaning and washing of utensils. Also the produce can be covered properly to reduce contact with flies. It can also be refrigerated or pasteurized or pasteurized at home or converted to cheese. 
46 Annals of the Social Science Council of Nigeria, No. 8, January-December, 1996

\section{Conclusion}

Southern in-migrants in many northern Nigeria cities are changing their diet. The change which for many of the in-migrants started in the late 1980s especially after the introduction of SAP, is from predominantly native diets of the in-migrants to the grainbased diets of the north. The observed change manifests patterns that relate both to ethnicity and socio-economic status of the in-migrants. The middle belt in-migrant whose native diets have some elements of northern diets and who according to the study are relatively poorer, changed their diets faster and more completely. Socio-economic hardship attending the structural adjustment programme is the stated reason for the change as it affects not only the availability of native food but more so its affordability.

Although the volume of long distance food trade may decline, total volume for the country may not suffer due to probable similar transition pattern among northern inmigrants in the south. The partial or selective adoption of the diets of the north may compromise the nutritional status of the newly acquired diets of the in-migrants. There is need for their newly acquired diet to be nutritionally balanced. Efforts need to be made to make the rejected but nutritious diets more acceptable to the in-migrants. Short-term shortfalls in food availability may be experience in urban areas but the favourable market incentive created by higher .demand for northern food crops should in time boost production to levels commensurate with demand.

\section{References}

Agboola, S. A. (1979) An Agriculture Atlas of Nigeria, Oxford: Oxford University Press.

Amuwd, K. (1992) "The International (and Domestic) Context of Democratic Transition in Africa: Roadblocks to Democray", in B Caron, A. Gboyega and E. Osaghae eds. Democratic Transition in Africa. Ibadan: CREDU

Cline-Cole, R.A., J.A. Falola, H.A.C. Main, J.J. Mortinore, J.E. Nichjol, and F.A. O'Reilly, (1990) Wood fuel in Kano, Tokyo: United Nations University Press.

Curtis, D.L. (1965) "Sorghum in West Africa", Field Crop Abstracts 18(3): 145-52.

Dear, M. and J.Wolch 1989. "How Territory Shapes Social Life". In J. Wholch and M. Dear (eds). The Power of Geography: How Territory Shapes Social Life. Boston: Unwin Hyman.

Hinderer, R. D. (1872) Seventy Years in Yoruba Country. London: Scclay, Jackson and Halliday.

IFPRI (1994) World Food Trends and Future Food Security. Washington: D.C. IFPRI. 
Dietary Adaptation of Southern In-migrants in Northern Cities of Nigeria 47

Mabogunje, A.L. (1968) Urbanization in Nigeria, London: University of London Press.

Munslow, B.(1991) "Review of Basil Davidson's The Fortunate Isles: A Study in Africa's Transformation" (Hutehinson, London, 1989). in Third World Quarterly 12 (3 \& 4) $1990 / 1991: 177-178$.

Nwafor, J.C. (1982) "Agricultural Zones", in K.M. Barbour, J.S. Oguntoyinbo, J.O.C. Onyemelukwe, J.C. Nwafor and M.O. Filani eds. Nigeria in Maps, London: Hodder and Soughton.

Odihi, J.O. (1993) "Nigeria-Niger Transborder Crossing During Environmental Crisis: Towards Distater Mitigation", In A.I. Asiwaju and B.M. Barkindo eds. NigeriaNiger Transborder Co-Operation, Lagos: National Boundary Commission.

Odihi, J.O. (1994a) "Spatial Cinstraints to Rural Development in Nigeria: Evidence from Benue State", Paper presented at the Workshop on Political Empowerment and Rural Development,, University of Maiduguri, 22-26 August.

Odihi, J.O. (1994b) "SAP and Changing Diets of Long Distance Immigrants in NE Cities of Nigeria." Journal of Social and Management Sciences 1 (2): 166-174.

Odihi, J.O. (1994c) "Urban Food Crisis in maiduguri", Annals of Borno 1/12:327-333.

Odihi, J.O. (1995) "Making Dams More Beneficial in .Northern Nigeria," Paper presented at the $3^{\mathrm{r}}$ "Workshop of Land Administration and Development in Northern Nigeria, Bayero University Kano. 12-15 March.

Okpata, A.O. (1992) "The Economy under SAP", Scandinavian Journal of Development Alternatives XI (3 and 4): 119-126.

Olatunbosun, D. (1975) Nigeria's Neglected Rural Majority, Ibadan: NISER

Olofhii, E.A. (1991) ed. Prospects and Problems of Irrigation in the Kano State Report of a Ford Foundation Research, Kano: Development of Geography, Bayero University.

Olofin, E.A. 1993. "Sustainable Irrigation Option for Nigeria: Larger or Small" in Nwa and Pradhan eds. Irrigation research Priorities, Kano: IIMI-Nigeria.

Olofin, E.A. (1994) "Constraint to River Regulation through Dams in the Sudano- 
48 Annals of the Social Science Council of Nigeria, No. 8. January-December, 1996

Sahelian Zone of Nihrtis," Paper read at the First International Conference for Development in the Arid Zone of Nigeria, University of Maiduguri, 19-25 June.

Onyemelukwe, J.O.C. (1992) "Major Food Crops", hi K.M. Barbour; J.S. Oguntoyinbo, J.O.C. Onyemelukwe, J.C. Nwafor and M.O. Filani eds Nigeria in Maps London: Hodder and Stoughton.

Onyemelukwe, J.O.C. and M.O. Filani, (1983) Economic Geography of West Africa, London: Heinemann.

Stein, H. and E.W. Nafziger, (1991) "Structural Adjustment, Human Needs and the World Bank Agenda" Journal of Modern Africa Studies 29 (1): 1973-189.

Steward, F. (1990) "Are Adjustment Policies in Africa Consistent with Long-run Development Needs?" Paper read at American Economic Association, Washington, D.C. 28-30 December.

Tucker, S. (1853) "Abeokuta and Sunrice within the Tropics", in A.J. Asiwaju and B.M. Barkindo eds. Nigeia-Niger Transborder Co-operation. Lagos: National Boundary Commission.

Udo, R.K. (1970) Geographical Regions of Nigeria, London: Heinemann. United Nations Development Programme (1992) Human Development Report, New York: UNDP. 